\title{
COM-POR, RASTROS E ESPECTROS DE DERRIDA
}

\author{
Georgia Amitrano*
}

\begin{abstract}
Resumo
O presente tex to tem como objetivo apresentar uma homenagem/admiração ao filósofo de Jacques Derrida, por ocasião dez anos de sua morte. Nesse sentindo, partindo da desconstrução das próprias palavras e termos usados pelo autor, este artigo é construído em uma admiração pessoal a Derrida. Não se circunscreve, assim, em um texto convencional, é um tributo, e como tal deve ser lido. Vai além ou por outra via daquela que os artigos acadêmicos costumam ser construídos. É uma escrita recheada de rastros e afetos. Uma 'homenagem' escrita por alguém que admira o pensamento de Derrida, que junto com ele busca ultrapassar as fronteiras da escritura, que se joga às margens da différance.
\end{abstract}

Palavras-Chave: Différance. Rastros. Espectros. Desconstrução. Escritura.

\section{Résumé}

Cet article vise à présenter un hommage / admiration du philosophe Jacques Derrida, à l'occasion des dix ans de sa mort. Dans ce sens, en partant de la déconstruction des mots mêmes et des termes utilisés par l'auteur, cet article est construit sur une admiration personnelle à Derrida. Il s'inscrit, donc, audelà d'un texte conventionnel. Il est, tout d'abord, un hommage et, à ce titre il doit être lu. Il va ainsi autrement que les articles universitaires se sont souvent construites. Il s'agit ici dune écriture pleine des traces et d'affects, «tribut» écrit par quelqu'un qui admire la pensée de Derrida, qui avec elle cherche à aller au-delà des frontières de l'Écriture, et donc, quelqu'un qui se risque aux rives de la différance.

\footnotetext{
Doutora em Filosofia pelo Programa de Pós Graduação em Filosofia da Universidade Federal do Rio de Janeiro (PPGF-UFRJ). Professora do Instituto de Filosofia da Universidade Federal de Uberlândia e Coordenadora do Programa de Pós Graduação em Filosofia (Mestrado) da Universidade Federal de Uberlândia. E-mail: georgiaamitrano@gmail.com
} 
Mots-Clés: Différance. Trace. Spectres. Deconstrucción. Ecriture.

\section{Breve apresentação}

Há muitos anos me apaixonei por pensamentos advindos de filósofos franco-magrebinos ao me deparar com um texto de Albert Camus intitulado La mort heureuse. Uma obra limítrofe entre o filosofar e o romance, uma obra que fala sobre vida e nos ensina a morrer. Escritos de alguém que viveu a miséria da Argélia, o mar e sol. Escritos de um homem capaz de pensar seu tempo e sua condição através da imagem da morte.

Mas o que seria essa Morte Feliz? Uma morte consciente, diria Camus. No último sopro, no derradeiro instante, a certeza de se ter realizado uma vida plena, com vicissitudes e prazeres. Uma vida que valera ser vivida. Uma constatação para poucos, diria eu.

É no influxo dessa vida que tem como fim último a morte, e talvez uma possível morte feliz, daquele que viveu de modo cabal sua existência como filosofia que este artigo é construído. Não como um discurso acerca do pensamento de um autor, mas, isto sim, como uma admiração àquele que viveu sob o sol, o mar e a miséria da mesma Argélia de Camus. Um tributo singelo a um pensador que desconstruiu a Filosofia e o filosofar instituídos em cânones fechados; um dizer adeus para um Filósofo que soube ler de Nietzsche, Marx, Husserl, Lévinas, Heidegger, dentre outros, o que estes tinham a nos dizer, o que nos inspirava. Um dizer adeus ao Filósofo que foi capaz de desconstruir autores e textos e dar significados outros a partir de seus espectros.

Esta admiração exposta a Jacques Derrida, assim, não se circunscreve em um texto convencional; afinal, é um tributo, e como tal deve ir além ou por outra via daquela que os artigos acadêmicos costumam ser construídos. É pessoal, recheada de sentimentos e afetos. É uma 'homenagem' escrita por alguém que admira o pensamento de Derrida, que junto com ele busca ultrapassar as fronteiras da escritura, que se joga às margens da différance, com esse $a$ grafado na nova escrita, donde o presente artigo ter características próprias.

Há no jogo da linguagem uma espécie de brincadeira conceitual, na qual me aproprio dos conceitos derridianos para escrever meu tributo. Palavras como rastros, espectros, différance, dentre outras, emergem como 
possibilidades dessa escritura. Uma tessitura que tenta desconstruir o próprio sentido dado ao termo homenagem. Uma composição, uma música traçada em ritmo diferenciado, encadeada a partir dos sentimentos a mim causados por Derrida.

À vista disso, o presente artigo guarda consigo toda a escrita das palavras ditas no momento da Homenagem, em $1^{\circ}$ outubro de 2015 na Universidade Federal de Uberlândia (UFU). Do mesmo modo, busca, em notas de rodapé e poucas citações, entreabrir os dizeres derridianos àqueles que desejam se regozijar em seus conceitos. Caminha, assim, através dos rastros por este argelino a nós deixados.

Não se trata, portanto, de mais um texto a ser lido estritamente como fonte de pesquisa; antes, é um território a ser explorado como possibilidade de novas tessituras, traços deixados como admiração. É um espaço de sensibilidade daquela que admira, que mira, e através deste admirar e mirar compõe algo a ser lido para, com e por Jacques Derrida.

$$
* * *
$$

Escrever é retirar-se. Não para a sua tenda para escrever, mas da sua própria escritura. Cair longe da linguagem, emancipá-la ou desampará-la, deixá-la caminhar sozinha e desmunida. Abandonar a palavra ${ }^{1}$

\section{Dez anos sem Jacques Derrida e um singelo tributo: minha admiração...}

Ao pensar em escrever para o evento em Homenagem a Derrida ${ }^{2}$, pelos dez anos de seu falecimento, em escrever minha singela homenagem, me deparo com algo muito especial, a singeleza própria de uma homenagem para um pensador incomum. Ademais, não basta ser Derrida, sou eu a escrever. Alguém que sempre seguiu rastros dos pensadores que leu, que tropeça nos traços, que traz consigo os sons de fantasmas de vários autores. Como, então, eu seria capaz de escrever para Derrida?

1 DERRIDA, J. A escritura e a Diferença, Editora Perspectiva, 2 ed. São Paulo, 2009, p. 91.

2 XVII SEMANA DE FILOSOFIA DA UFU. Colóquio Internacional, Homenagem a Jacques Derrida, ocorrido em $1^{\circ}$ de Outubro de 2015, na Universidade Federal de Uberlândia. 
Na duplicidade desta difícil escrita, busco então ficar atenta a Derrida. Mas que filósofo é esse que a cada nova leitura me parece dizer que quer deixar rastros e não discípulos? Que me obriga a pensar e desconstruir, desmontar, decompor palavras e pensamentos. Um filósofo que me parece não querer ouvir seu pensamento apenas repetido e, tampouco, somente refletido; antes, parece desejar ter seu pensamento também desconstruído. Afinal, ele é o pensador da Différance $e^{3}$. O pensador do jogo dos diferentes significados das palavras, da heterogeneidade que governa a produção de significados textuais.

É assim, então, que construo esse texto, na Différance Derrida. E nessa Différance, de cara percebo que não posso homenageá-lo. Como fazê-lo se na construção da palavra homenagem, na sua origem provençal, está a forma de um homem prestar vassalagem a outro? E, por mais que se tenha dado outro sentido, ainda, omenatge significaria o "vassalo, o homem de armas que deve sua fidelidade ao suserano" ${ }^{4}$. Definitivamente, isto não serve a Derrida.

Vou, então, admirar Derrida. Admirar sua obra e seu pensamento. Contudo, esta admiração não se dará no simples repetir ou explicar seu pensamento; antes, está nos rastros que ele me faz seguir, na espectral companhia desse fantasma que me acompanha e assombra faz alguns anos, e que também me ajuda a tracejar um pensamento mais livre das amarras canônicas.

3 Différance, termo francês cunhado por Jacques Derrida, (com 'a' no lugar de 'e') é um neologismo extraído da palavra francesa différence (semelhança fonética e alteridade gráfica); o 'a' deve, segundo ele, dizer mais do que o 'e', deve adicionar, ao sentido grego da palavra, o latino, mas não somente no sentido de atribuir- lhe um caráter polissêmico; deve trazer a diferença a seu lugar devido na linguagem, à radicalidade de seu sentido. A différance (com a) deve significar diferencialidade anterior a toda diferença determinada. A toda diferença com 'e', a toda presença. Différance faz um jogo com o fato de que a palavra francesa différer pode significar tanto "diferir" ("postergar" / "adiar", em termos diacrônicos, o que nos remete para uma temporalização, para atividade, para a fala, para o uso, para gênese) quanto diferenciar (em termos Saussureanos, onde os termos se determinam reciprocamente, não detendo um significado "em si", mas na relação diferencial que estabelecem com os demais, sincronicamente, o que nos remete para um espaçamento, para passividade, para língua, para esquema, para a estrutura). Derrida usa pela primeira vez o termo différance no seu texto de 1963 Cogito et histoire de la folie.

4 Tanto a palavra homenagem quanto o verbo derivado dela, homenagear, têm origem no provençal antigo omenatge.( omin, homen). 
Escolho, assim, a sensibilidade, aquela que se constitui desde os fulcros da Corporeidade, da Intuição, da Afetividade. À vista disso, é nesse processo de possíveis modos de dizer, de línguas diferentes, que miro para esse outro que a mim aparece com o rosto de Derrida, e isso de maneira a me aproximar e averiguar, indagar e, finalmente, admirar.

É a admiração o que me faz ouvir essa voz fantasmagórica, esse sentimento de assombro, de surpresa ou espanto diante de diversas situações. É a admiração, assim, o que me faz mais filósofa a cada dia; afinal, na Filosofia, o admirar-se e o espantar-se são o que principia o começar a filosofar, o thaumazein $^{5}$. Em outras palavras, é no processo atrativo, admirativo que não atravessamos indiferentes ante qualquer coisa. A admiração, assim, nos coloca em movimento, nos obriga a problematizar o que antes parecia evidente, como o bom e velho gato branco ${ }^{6}$ de Derrida que o observa nu durante seu banho, procurando esclarecer o que se apresenta como obscuro.

Aqui, portanto, vou admirar ou manifestar minha admiração por Derrida, não simplesmente por seus escritos, por seu legado filosófico linguístico, mas por me ajudar a não perder minha capacidade de me espantar, de me regozijar com um forte sentimento de prazer diante de alguém ou algo que considero extraordinário. Essa disposição emocional, portanto, me permite olhar para além da obviedade e decompor velhos conceitos, quebrando um a um até compor novas significações possíveis, novos modelos de entendimento que no futuro também devem ser desconstruídos.

5 Lembremos de uma frase no Teeteto na qual a filosofia começa com a admiração. Nesse diálogo, Platão descreve uma cena em que o jovem Teeteto fica admirado quando compreende um dos argumentos sobre a sensibilidade apresentado por Sócrates. A fim de explicar o sentimento de Teeteto, Sócrates diz que o princípio da filosofia é a experiência de admiração. Platão ao referir-se a esta admiração, como um pathos, um estado interior que sentimos quando algo nos arrebata, aponta para uma experiência de encantamento, uma paixão que afeta, mais que aos outros homens, o filósofo. Só assim o filósofo é eminentemente humano; pois o homem é feito de modo a viver no thaumazein. No verbo thaumazein encontra-se a raiz thea que significa ver, olhar. Ver e olhar atentamente, como arrebatado em paralisia.

6 Derrida confessa uma dificuldade de reprimir um movimento de pudor, uma vergonha de ter vergonha. Assim, desenvolve todo o seu ensaio $O$ animal que logo sou diante de um momento singular: Contra o mal-estar que pode haver em encontrar-se nu, o sexo exposto, nu diante de um gato que nos observa sem se mexer, apenas para ver (DERRIDA, J. $O$ animal que logo sou. Trad. Fábio Landa. São Paulo: Ed. Unesp, 2002, p. 15). 


\section{O com-por e os rastros espectrais}

Com um título que começa por com-por, brinco com as palavras; afinal, no jogo das preposições, com introduz um argumento realizado com o papel temático de Instrumento; bem como, no léxico-conceitual, com constitui um marcador gramatical do estatuto argumentativo do sintagma que introduz. Mas, o com, para além de tudo isso, implica estar junto. Já o por é uma preposição que, dentre uma variante possível, implica causa ou o meio pelo qual sou capaz de realizar uma dada ação. Sendo assim, o meu com-por junta coisas diferentes de modo a produzir, criar, inventar, construir, e depois, desconstruir. E é com e por Derrida que tracejo minha escrita. E ao tracejar, me obrigo a falar do traço.

Ora, com a palavra traço ${ }^{7}$ (rastro), Derrida nos remete à noção de "arbitrário". E é na arbitrariedade, no inesperado, naquilo que não pode ser previsto, que se observa o fato de um dado significante não depender efetivamente da livre escolha daquilo que se fala, bem como este não possuir uma amarra necessária com o que significa. Em outras palavras, aquilo que temos como tangível, perceptível, o material do signo nem sempre se liga ao conceito abstrato a ele imposto.

O traço, assim, não articula a sua possibilidade ao campo do "ente-presente". "É preciso pensar o rastro antes do ente". Em um permanente vir a ser, o signo, como traço, atravessa a etapa do símbolo, e isso de tal modo que "é preciso dizer o que Saussure não disse: não há símbolo e signo, e sim um vir-a-ser-signo-do-símbolo".

E o traço é o rastro. E rastro é a abertura para a exterioridade em geral. A temida abertura para "o fora" que a metafísica rejeitou, a enigmática abertura para o outro e a desconstrução da presença plena no logos.

E o pensamento de Derrida é um dos rastros que persigo. Um pensamento que é capaz de me fazer jogar dentro do movimento. Contudo, não é qualquer movimento; antes, é o da desconstrução ${ }^{9}$. Um movimento que

7 Traço é um conceito derridiano, como différance ou escritura, para compreender como o processo cognitivo sobre o mundo que nos cerce é constituído por uma linguagem-escritura.

8 DERRIDA, J. Gramatologia. São Paulo: Perspectiva, 2004. p. 58.

9 Desconstrução é o termo proposto por Jacques Derrida, nos anos sessenta, para um processo de análise crítico-filosófica que tem por objetivo imediato a crítica da metafísica ocidental e da sua tendência para o logocentrismo, incluindo a crítica de certos conceitos (o significado e 
implica uma não-origem, que me desloca do dado para um vestígio, um rastro (trace) antes de outro suposto vestígio.

É a noção de rastro, portanto, não apenas fundamental para a minha admiração derridiana, como também é no com e por Derrida que se observa o quão esta noção de traço/rastro se torna fundamental para deslocar qualquer problema que seja posto como sempre dado. À vista disso, para pensar o rastro é sempre preciso primeiro abdicar do sistema conceitual metafísico-teológico (e também teleológico) e de suas implicações sempre dicotômicas. Afinal, o rastro (trace) como rastro vem necessariamente sempre a apagar-se no texto da metafísica que, todavia, o transporta. $\mathrm{O}$ rastro, assim, diz do apagamento da presença, da sua impossibilidade como tal.

O rastro não é somente a desaparição da origem, ele quer dizer aqui [...] que a origem não desapareceu sequer, que ela jamais foi reconstruída a não ser por uma não-origem, o rastro, que se torna assim, a origem da origem. [...] O rastro (puro) é a différance. ${ }^{10}$

O conceito de rastro em Derrida evoca o movimento da différance, pois o rastro anuncia e difere. Anunciando um já lá (déjà-là) que, concomitantemente, impede, adia a realização absoluta. Ou seja, o rastro coloca a impossibilidade de uma origem pura e de um "fechamento do devir". Todo rastro é rastro de rastro (trace de trace).

Com Derrida - este fantasma, espectro que me deixa rastros - me dou conta mais uma vez ser necessário colocar em xeque os pressupostos fundamentais de toda uma tradição, em especial, a da metafísica da presença. Ou seja, apontar o dedo na ferida, o fato da inexistência de $A$ Filosofia.

Como disse Derrida:

o significante; o sensível e o inteligível; a origem do ser; a presença do centro; o logos, etc.) que tal tradição havia imposto como estáveis. A desconstrução não é um método, o "método desconstrutivo" como é comum se dizer. Também não pode ser compreendida como uma teoria previamente construída sobre o ser, as coisas em geral, o homem, a razão, a história etc. Um "pensamento da desconstrução" nada está subordinado a uma teoria prévia. Trata-se, antes, de um trabalho de pensamento que procura investigar os limites de toda teorização e, portanto, de toda pretensão de totalização que se encontra operante em um discurso. O próprio Derrida afirma que a desconstrução consiste em um pensamento sempre comprometido em pensar a origem e os limites da questão "o que é?".

${ }^{10}$ DERRIDA, 2004, p.75-77. 
$\mathrm{Na}$ verdade, tudo quanto desde há muito tempo me tem, digamos, interessado - a título de escrita, do rastro, da desconstrução do falogocentrismo e "da" metafísica ocidental (que, e embora o tenham repetido até à saciedade, eu nunca identifiquei como uma única coisa homogênea e vigiada pelo seu artigo definido no singular, disse tantas vezes o contrário e tão explicitamente!), tudo isso não pôde deixar de provir desta estranha referência a um "algures" de que o lugar e a língua me eram a mim próprio desconhecidos ou interditos. ${ }^{11}$

Não esqueçamos que ao falarmos de uma "metafísica da presença", falamos de linguagem, de referência. É o conceito de signo que está aqui pontuado, pois este conceito foi pensado pela tradição como formado por um significante que se refere a um significado. Donde, esse signo, para Derrida, se mostrar como uma presença original diferida, ou seja, a substituição da coisa presente (da coisa mesma) por ele, o que implicaria um caráter ao mesmo tempo secundário e provisório a tal substituição. Secundário, já que deriva de uma presença original. Provisório, perante a presença original e por representá-la enquanto ela está ausente, ou seja, mediá-la.

Aqui é a linguagem e a escrita que se apresentam de modo novo às minhas velhas expectativas. Com Derrida capturo uma necessidade de desconstruir o velho padrão de linguagem ao qual sempre me senti confortável. Isso, todavia, não implica me fazer pensar em uma reabilitação da escrita, em uma inversão da ordem de dependência desta com a fala; antes, no estudo do estrato puramente gráfico do texto, é preciso mostrar que este está aberto a pesquisas inéditas e fecundas.

Nesta dinâmica nova, a necessidade de uma arquiescritura ${ }^{12}$ se apre-

${ }^{11}$ Certes, tout ce qui m'a, disons, intéressé depuis longtemps - au titre de l'écriture, de la trace, de la déconstruction du phallogocentrisme et de "la" métaphysique occidentale (que je n'ai jamais, quoi qu'on en ait répété à satiété, identifié comme une seule chose homogène et surveillée par son article défini au singulier, j'ai si souvent dit le contraire et si explicitement !), tout cela n'a pas pu ne pas procéder de cette étrange référence à un "ailleurs" dont le lieu et la langue m'étaient à moi-même inconnus ou interdits. (DERRIDA, 1996, p. 131, grifos nossos).

${ }^{12}$ Termo cunhado por Jacques Derrida, no interior da sua teoria sobre uma gramatologia aplicada, que é uma espécie de ciência geral da escrita, e que resiste a uma definição fixa. Derrida rejeita a ideia de se tratar de um conceito aplicável. A desconstrução propõe uma nova forma de pensar e formular a escrita, mas não quer colocar em seu lugar outra 
senta, uma escrita que precede à fala e que não aparece como objeto de uma ciência. Uma escritura que emerge como aquilo mesmo que não se deixa reduzir sob a forma de presença, enquanto condição de todo o sistema linguístico ele mesmo.

Sim, Derrida me mostra desvios aos quais sempre persegui, e os seus rastros me fazem os encontrar. E um desses rastros, apenas um deles, é a linguagem.

Há ainda tantos outros rastros a perseguir!

Mas voltemos aos rastros que persigo, aos rastros que me impelem a novos conhecimentos e estudos, e que me deixam rastros de rastros de outros pensadores.

Afinal,

Sem uma retenção na unidade minimal da experiência temporal, sem um rastro retendo o outro como outro no mesmo, nenhuma diferença faria sua obra e nenhum sentido apareceria. Portanto, não se trata aqui de uma diferença constituída, mas, antes, de toda determinação de conteúdo, do movimento puro que produz a diferença. O rastro (puro) é a diferência. Ela não depende de nenhuma plenitude sensível ou visível, fônica ou gráfica. É, ao contrário, a condição destas [...]. Ela permite a articulação dos signos entre si no interior de uma mesma ordem abstrata - de um texto fônico ou gráfico, por exemplo - ou entre duas ordens de expressão. ${ }^{13}$

Ora, o tom de meu trabalho sempre foi o da política e o da ética. E, nesse tom dado, dificilmente me prendo ao autor $\mathrm{A}$ ou $\mathrm{B}$, roubo-lhes o que sinto de melhor, tenho-os como espectros, anões fantasmas que zumbem em meu ouvido. E com Derrida não seria diferente. Os zumbidos espectrais deste autor do qual sigo rastros me trouxeram outra dimensão do animal, da besta e do soberano. Puseram-me no desconforto de uma nova escritura, me

formulação definitiva. A arquiescritura deve estar sujeita a uma investigação contínua. Assim sendo, quando falamos de arquiescritura falamos da escrita que precede a fala e nela se concretiza. Não se trata da definição tradicional da escrita como registro gráfico nem se pressupõe a referência a um mundo exterior ou ulterior ao texto. É ao que sobrevive a estes limites tradicionais de significação que Derrida chama arquiescritura.

${ }^{13}$ DERRIDA, 1973, p. 76. 
fizeram as costas pesadas por enchê-las dos anões espectros que ele Derrida também carregava.

Com Derrida veio Benjamin, Lévinas, Schmitt, entre outros. Por Derrida me tornei herdeira, herdeira de uma herança altamente intricada, que submerge inúmeras estratégias de apropriação. Ou, como diz Derrida, de ex-apropriação. Tornei-me herdeira de desdobramentos políticos, éticos e estéticos aos quais DEVO profanar na decomposição e desconstrução de cada texto, escritura-linguagem que me chega.

Derrida me fez uma herdeira profana, pois não apenas as suas obras me obriga a carregar e desconstruir, como a tudo que já li... Fantasma pesado esse Derrida com seus espectros. Fantasma, espectro ${ }^{14}$ do qual agora tenho uma filiação e sou herdeira.

Mas como disse, herdar é, por natureza, expropriar, ou ex-apropriar. É claro que se pode fazer qualquer leitura de um texto, mas para que ela seja vista como minimamente adequada, é preciso seguir certos protocolos interpretativos a fim de se chegar a uma verdadeira invenção. Sendo assim, a verdadeira herança está em saber: em 'saber saber', ainda que saber deva se aproximar de uma forma instigante e expropriadora de não-saber, e tudo isso para não correr-se o risco do enrijecimento ou engessamento, seja ele do texto ou do pensamento ex-apropriado.

14 "O espectro é uma incorporação paradoxal, o tornar-se corpo, uma certa forma carnal e fenomenal do espírito. Torna-se algo difícil de nomear: nem espírito nem corpo, ou tanto um como outro. Pois é a carne e a condição de fenômeno que possibilitam ao espírito a sua aparição espectral, mas que desaparecem imediatamente na aparição, na própria chegada do revenant ou retorno do espectro. Existe algo que desaparece, que se afasta na própria aparição enquanto reaparição do que partiu.... [O espectro] é alguma coisa que, precisamente, não se conhece, e não se sabe, precisamente, se ele é, se existe, se responde a um nome e se corresponde a uma essência. Não se conhece: não por ignorância, mas porque esse não-objeto, esse presente não-presente, esse estar-lá de alguém ausente ou que partiu já não pertence ao controle do conhecimento. Pelo menos não pertence mais àquilo que pensamos entender pelo nome de conhecimento. [O espectro é] uma coisa que não pode ser nomeada, ou que quase não pode ser nomeada, "esta coisa", mas esta coisa e nenhuma outra, esta coisa que nos olha, que nos diz respeito [qui nous regarde] chega para desafiar tanto a semântica quanto a ontologia, tanto a psicanálise quanto a filosofia. (Marcelo: O que? Essa coisa apareceu outra vez na noite de hoje? Eu não vejo nada). A coisa permanece invisível, é o nada visível. Essa coisa que não é uma coisa olha para nós e vê que não a vemos, mesmo quando está lá. A isso chamaremos o efeito de visor: nós não vemos aquele que olha para nós" (DERRIDA, 1994, p. 6-7). 
A herança não é jamais dada, é sempre uma tarefa. Permanece diante de nós, tão incontestavelmente que, antes mesmo de querê-la ou recusá-la, somos herdeiros, e herdeiros enlutados, como todos os herdeiros. ${ }^{15}$

E, nesta herança derridiana, o que talvez mais me toque e me traga o peso amargo do herdado, é pensar uma ética da alteridade. É pensar na hospitalidade e nas suas impossibilidades práticas por vezes. Volto-me, então, a outro espectro que zumbi rastros em meus ouvidos, Rosa Luxemburgo, cujas palavras ecoam e nos despertam para o extraordinário do tempo. Tempo este nosso que apregoa a exclusão, a exceção em nome da ideologia humanitária.

Ah essas heranças!!!!

Heranças que espelham aos incautos um futuro ${ }^{16}$, mas não é disso que se trata, nem mesmo pode ser pensada como algo a nos fazer agraciados.

Infelizmente, nesta minha Admiração a Derrida, o tempo é curto, e outros textos ou artigos eu já os escrevi ou ainda escreverei. Aqui, tenho de escolher uma parte da herança derridiana. Que rastros ainda há tempo de seguir por hora?

Escolho, então, me mantendo à linguagem e à escritura, a poesia como literatura e pintura. Caminho por entre as formas estéticas e, com Derrida, tracejo uma estética setorial, na qual a obra de arte é apresentada a partir de certo arquétipo generativo capaz de atualizar uma dinâmica desconstrutora.

No meu ato de admirar, na minha com-posição, vou buscar o encontro. E é no encontro entre Derrida e Joyce que vislumbro um acolhimento ao outro em sua outridade literária. Afinal, o ato da hospitalidade só pode ser poético, como dissera um dia Derrida a Anne Dufourmantelle ${ }^{17}$.

Para além disso, há uma razão no fato de um texto ser efetivamente um texto. Afinal,

\footnotetext{
${ }^{15}$ Ibidem, p. 33.

${ }^{16}$ Toda a questão do por-vir, de que ratará sobretudo a partir dos anos 1990, passa pela necessidade de distinguir com clareza a noção de por-vir (à-venir) da de futuro (futur), em francês. O por-vir derridiano de algum modo está vindo ou mesmo já está aí, não se anuncia num amanhã utópico, redentor.

${ }^{17}$ DERRIDA, 2003, p. 04.
} 
Um texto só é um texto se ele oculta ao primeiro olhar, ao primeiro encontro, a lei de sua composição e a regra de seu jogo. Um texto permanece, aliás, sempre imperceptível. A lei e a regra não se abrigam no inacessível de um segredo, simplesmente elas nunca se entregam, no presente, a nada que se possa nomear rigorosamente uma percepção. ${ }^{18}$

É a partir do ensaio Ulysse Gramophone ${ }^{19}$ que penetro em uma possível associação com uma não desconstrução dos textos literários por Derrida; afinal, como desconstruí-los se estes já se encontrarem assombrados pela invisibilidade dos espectros? Não podem ser desconstruídos porque já se desconstroem desde sempre. Como um dia afirma Derrida, "existe desde sempre desconstrução, operando em obras, especialmente em obras literárias".

Ademais, Derrida também nos apresenta a relação existente entre um cartão postal e uma garrafa arrolhada com uma mensagem lançada ao mar. Neste gesto do envio, há sempre uma promessa de encontro, contudo este encontro não é garantido. A escritura tecida pela mensagem nos remete a um lugar imaginário, sem nome, no qual não há um destinatário preciso. Mas não é pelo fato de ser imaginário que a verdade não é dita. Esta é arquivada na garrafa e no desejo do encontro.

Derrida ainda, em uma releitura de Sócrates em Platão, recoloca as questões que envolvem a representação e a verdade. Na distinção entre os dois tipos de imagem postos por Platão, nos voltamos à noção de eikon e o phantasma, isto é, entre cópia e simulacro. Distinção esta na qual se colocou no traço ou na escritura o perigo do simulacro, sendo visto por essa tradição como suplemento espacial da "verdadeira repetição".

Mais além, Derrida retoma os pontos que se unem à noção de poesia a partir de Mallarmé. Há, de fato, uma problemática da representação que se desenha no intervalo entre a escritura, a fala, a pintura-escritura e o seu próprio fazer-se. Há um gesto ambivalente na escrita literária que se desenha em Derrida, tanto como uma afirmação da existência, a despeito da rigidez do real, quanto uma recusa de complacência para com qualquer que seja o objeto.

\footnotetext{
${ }^{18}$ DERRIDA, 2005, p. 07.

${ }^{19}$ DERRIDA, 1987.
} 
Ora, as reflexões de Derrida se deixam emaranhar e redimensionar através de seu contínuo diálogo com literatura e a pintura. Derrida nos oferece, assim, uma estética serial, como afirma Rösch, na qual a obra de arte é apresentada a partir de certo arquétipo generativo capaz de atualizar uma dinâmica desconstrutora. A arte, no modelo desconstrutivista derridiano, nos põe diante de um a infinidade de discursos polimorfos, em cujo polimorfismo faz a obra escapar. Em seu pensamento, a origem da arte emerge como uma hetero-afecção atada à visibilidade. Tal observação derridiana pode ser mais bem compreendida no momento em que nos voltamos a um texto de Artaud, no qual o artista se debruça sobre a pintura dos girassóis de Van Gogh.

É a natureza nua e pura vista exatamente como ela se revela, quando se sabe chegar suficientemente perto dela. [...] estas cores sem cerimônia, que são todo um acontecimento, onde cada pincelada de Van Gogh na tela é pior que um acontecimento. [...] Ele [Van Gogh] fez, sob a representação, brotar um ar, e nele encerrou um nervo, que não estão na natureza, que são de uma natureza e de um ar mais verdadeiros que o ar e o nervo da verdadeira natureza. [...] seus girassóis de ouro brônzeo estão pintados; estão pintados como girassóis e nada mais, mas para entender um girassol ao natural, é preciso agora voltar a Van Gogh, assim como para entender uma tempestade ao natural, um céu tempestuoso, uma planície ao natural, não se poderá mais deixar de voltar a Van Gogh. ${ }^{20}$

Para Derrida, essa dimensão do olhar de Artaud condensa toda uma teoria sobre a gênese da arte, acenando para o fato de que a pintura é capaz de transpor o pintor e o seu meio, sobrevindo ao outro lado da linha de separação, justamente, ao inscrever em si a verdade da natureza. Ademais, é possível afirmar que Artaud e seu Van Gogh não se separam na pintura e no teatro para Derrida. Afinal, para o pensador franco argelino, no seu ensaio dedicado aos desenhos e retratos de Artaud, é perceptível que estes são tratados como escritos desenhados, que conjugam a potência imprecatória das palavras, a força visual dos signos gráficos e a experiência do fogo voluntariamente aplicado ao papel. Há um pictórico que "Enlouquece o subjétil”.

${ }^{20}$ ARTAUD, 1995, p. $277 ; 279 ; 280 ; 281$. 
No processo de desconstrução derridiano, o que se pode retirar é uma verdade fictícia de uma "verdade sem verdade da verdade". De fato, se a obra de arte instala uma verdade no mundo, esta pode ser traduzida nas palavras de Cézanne ${ }^{21}$ : "Je vous dois la vérité en peinture, et je vous la dirai", as quais são lembradas por Derrida em $A$ verdade em Pintura. Contudo, tal verdade, para Derrida, é da ordem do traço e da escrita que grifam o paradoxo de uma verdade não verdade já articulada.

Ao fim, a desconstrução derridiana também profana. Ao "enlouquecer o subjétil", Derrida redesenha traços e rastros de uma "pictografia", de modo a apontar, via Artaud, para uma arte transcrita, que transgride e conjuga pela pintura, pelo desenho e pela escritura. Não há paredes divisórias, "nem a das artes nem a dos gêneros, nem a dos suportes nem a das substâncias." A palavra não reconduz a uma "proto-escritura na qual projetamos todos os nossos mitos de origem"; antes, insinua a "trajetória daquilo que literalmente está apto a atravessar o limite entre a pintura e o desenho, o desenho e a escritura verbal, de uma maneira geral, as artes do espaço e as outras" ${ }^{\prime 2}$.

$$
* * *
$$

Finalizo esse texto deixando para Derrida outros espectros, assombros meus que me fazem correr atrás de novos rastros e permitir que outros também os carreguem.

É com a Poesia de Paulo Leminsk que encontro outros traços, que vejo a profanação linguística, que atento para o doce perigo da linguagem enquanto escritura. Contorcendo-se sobre si, as letras, as falas, na "poligrafonia" do texto nos fazem bem mais que mirar.

Em um livro para crianças - se de fato se pode falar da existência de algum livro que seja apenas para crianças - Leminsk fala do bicho alfabeto, constrói imagética e foneticamente um novo ser desconstruído do próprio alfabeto. Aqui, permito-me deixar aos que perseguirão Derrida um dizer desconstruído na poesia.

É com os versos de Leminski que, então, falo daquele que:

${ }^{21}$ Carta a Emile Bernard, de 23 de Outubro de 1905. (Cf. CÉZANNE, 1978).

${ }^{22}$ DERRIDA, 1998, p. 47. 
tem vinte e três patas/ou quase

por onde ele passa

nascem palavras

e frases

com frases

se fazem asas

palavras

o vento leve

o bicho alfabeto

passa

fica o que não se escreve $e^{23}$

\section{Referências}

ARTAUD, Antonin. Linguagem e vida. Tradução de Jacó Guinsburg, Sílvia Fernandes, Regina Correa Rocha e Maria Lúcia Pereira. São Paulo: Perspectiva, 1995.

CÉZANNE, Paul. Correspondence. Recueillie, annotée et préf acée par John Rewald. Édition révisée et augmentée. Paris: Gra sset et Fasquelle, 1978.

DERRIDA, J. Gramatologia. São Paulo: Perspectiva, 2004.

. A farmácia de Platão. Tradução de Rogério da Costa. São Paulo: Iluminuras, 2005.

. Anne Dufourmantelle convida Jacques Derrida a falar da hospi-

talidade. Tradução de Antonio Romane. São Paulo: Escuta, 2003.

. Espectrosde Marx: o estado da dívida, o trabalho do luto e a nova Internacional. Tradução de Anamaria Skinner. Rio de Janeiro: RelumeDumará, 1994.

. Gramatologia. São Paulo: Perspectiva, 1973.

${ }^{23}$ LEMINSK, 2014, p. 10-11. 
. Ulysse gramophone - Deux mots pour Joyce. Paris: Galilée, 1987. . Le monolinguisme de l'autre. Paris: Galilée, 1996. . Enlouquecer o subjétil. São Paulo: Editora Unesp, 1998. . A escritura e a diferença. 2. ed., São Paulo: Perspectiva, 2009. . O animal que logo sou. Tradução de Fábio Landa. São Paulo: Unesp, 2002.

LEMINSK, Paulo. Obicho alfabeto. São Paulo: Companhia das Letras, 2014.

Data de registro: $14 / 04 / 2015$

Data de aceite: 22/04/2015 